\title{
Experimental study of toluene decomposition by combination of barrier discharge plasma and UV light
}

\author{
P. Robert ${ }^{1}$, K. J. Sung ${ }^{2}$, A. Chul ${ }^{2}$, Y. Y. Soon ${ }^{2} \&$ V. Demidyuk ${ }^{1}$ \\ ${ }^{1}$ Chemistry department, Lomonosov Moscow State University, Moscow, \\ Russia \\ ${ }^{2}$ Sudo Premium Engineering Co., LTD, Seoul, Korea
}

\begin{abstract}
The combination of dielectric barrier discharge plasma (DBD) and ultraviolet irradiation (UV) on the decomposition of toluene was studied.

The decomposition rate of toluene by combination of DBD and UV, as well as reaction products were studied in a $0.5 \mathrm{~m}^{3}$ stainless steel closed chamber. The synergetic effect was found in toluene decomposition by combination of DBD and UV. This parameter increases sharply in comparison to the decomposition rate of toluene by both DBD and UV separately.

Ion cluster concentration was also increased whereas ozone accumulation concentration was dramatically decreased.

An obtained phenomenon was discussed due to the difference of oxidation rates between ozone and hydroxyl radicals which are produced by the decomposition of ozone by UV light.

Keywords: plasma, toluene decomposition, UV light, ozone, ion cluster.
\end{abstract}

\section{Introduction}

Plasma air treatment is a subject of many investigations to use it for indoor air pollution control [1-4]. The main advantage of it is a decomposition of gaseous air pollutants at room temperature. The decomposition rate of air pollutants is mainly depended on a discharge voltage. The higher discharge voltage the higher decomposition rate.

At the same time a decomposition rate of contaminants by plasma treatment accompanied to the formation of minor amount of harmful by-products such as 
ozone, carbon monoxide, and aerosol particles [5, 6]. The quantity of them also depends on discharge voltage or supplied energy into plasma. The higher supplied energy the higher the amount of by-products.

In order to overcome this duality the researchers $[7,8]$ paid their attentions to develop combination systems based on plasma treatment and other additional methods like catalyst [7], water scrubber [8].

In the study [9] was shown that the utilization of ozone catalyst coated onto the fan wheel in plasma air cleaner allowed the discharge voltage to be increased up to $20 \%$ without changing an ozone concentration in outlet of air cleaner.

Combination of dielectric barrier discharge plasma (DBD) and ultraviolet irradiation (UV), hereafter named as DBDUV on the decomposition of toluene was experimentally studied. The decomposition of toluene by (DBD) as well as by UV was also studied for comparison.

\section{Experimental}

\subsection{Reaction chamber}

A closed stainless steel chamber $\left(0.5 \mathrm{~m}^{3}\right)$ was used in this experiment, fig. 1 . Inside of a chamber was placed air cleaner system consisting of dielectric barrier discharge device and ultraviolet lamp, fig. 1. The DBD device was the glass tube coated inside with a silver film as a high voltage electrode and a stainless steel net covering the glass as a ground one. The high voltage $60 \mathrm{~Hz}$ frequency AC power supply was used for formation of barrier discharge plasma in surrounding of glass tubes. The ultraviolet lamp was Hg-lamp "PL-L 18W" (Philips).

Gaseous toluene was prepared by bubbling toluene liquid with air at $285 \mathrm{~K}$ and injected into chamber to form a known initial concentration of toluene. Contents of the chamber were mixed by fan with $60 \mathrm{CMH}$, continuously.

\subsection{Analyses}

The alteration of toluene concentration in the chamber during reaction time was controlled by "PGM-7420", $\mathrm{CO}$ and $\mathrm{CO}_{2}$ by"PGM-5210" IAQRAE Rae analyzers (USA) and Gastec glass tube (Japan), and ozone concentration by "49C ozone calibrator" (USA) and Gastec glass tube.

Accumulation of ion produced by DBD, UV, and DBDUV were controlled by ion meter "T-111" Transjionic AB (Sweden).

The decomposition rate (DR) of toluene was determined by:

$$
\mathrm{DR}=\frac{\left(\left[\mathrm{C}_{7} \mathrm{H}_{8}\right]_{\mathrm{O}}-\left[\mathrm{C}_{7} \mathrm{H}_{8}\right]_{\mathrm{I}}\right.}{\left.-\cdot-\mathrm{C}_{7} \mathrm{H}_{8}\right]_{\mathrm{I}}}
$$

where $\left[\mathrm{C}_{7} \mathrm{H}_{8}\right]_{\mathrm{O}}$ and $\left[\mathrm{C}_{7} \mathrm{H}_{8}\right]_{\mathrm{I}}$ are the initial and the current toluene concentrations, respectively. 
Oxidation rate of toluene was described as a parameter (S) which is defined by:

$$
\mathrm{S}=\frac{\left(\left[\mathrm{CO}_{2}\right]_{\mathrm{I}}-\left[\mathrm{CO}_{2}\right]_{\mathrm{O}}\right)+\left[\mathrm{CO}_{\mathrm{I}}\right]}{-\left(\left[\mathrm{C}_{7} \mathrm{H}_{8}\right]_{\mathrm{O}}-\left[\mathrm{C}_{7} \mathrm{H}_{8}\right]_{\mathrm{I}}\right)^{* 7}}
$$

where $\left[\mathrm{CO}_{\mathrm{I}}\right],\left[\mathrm{CO}_{2}\right]_{\mathrm{I}}$ and $\left[\mathrm{CO}_{2}\right]_{\mathrm{O}}$ are the current and the initial carbon monoxide, carbon dioxide concentrations, respectively; $\left[\mathrm{C}_{7} \mathrm{H}_{8}\right]_{\mathrm{O}}$ and $\left[\mathrm{C}_{7} \mathrm{H}_{8}\right]_{\mathrm{I}}$ are the initial and the current toluene concentrations, respectively.

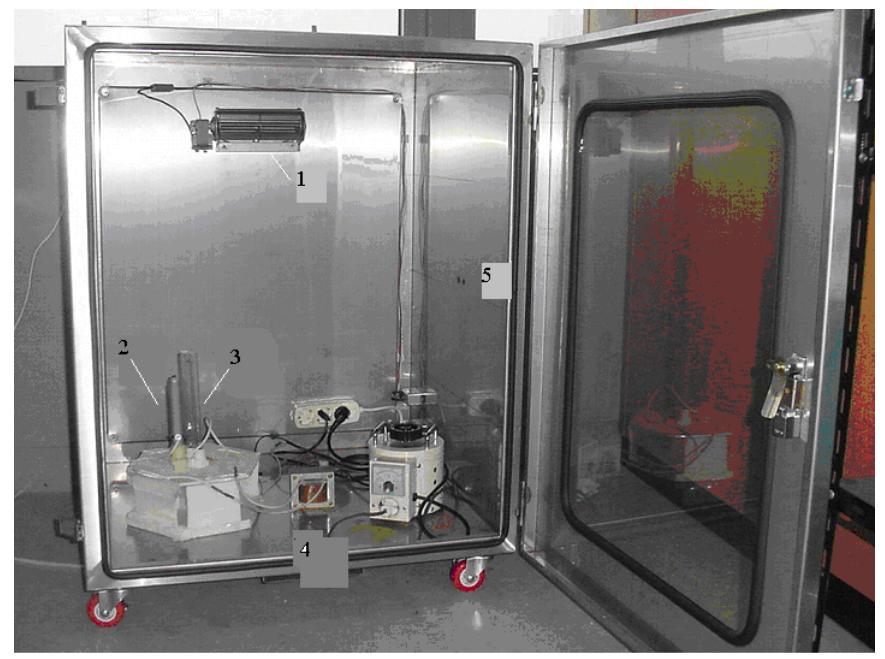

Figure 1: Experimental system for toluene decomposition: 1- Fan. 2 - DBD device; 3 - UV lamp; 4 - High voltage transformer; 5 - Stainless steel chamber.

\section{Results}

\subsection{Efficiency improvement by UV irradiation}

In order to improve DBD method for removal of indoor VOCs, the decomposition of toluene was studied in the presence of UV. In fig. 2 are shown the decomposition of toluene by three methods: DBD, UV, and DBDUV. High voltage supplied to barrier discharge tube was $2.8 \mathrm{kV}$. The decomposition rates of toluene by DBD as well as UV irradiation are nearly the same. Maximum decomposition rate is not higher than $7.5 \%$ for both cases for 2 hours. However, this value is dramatically increased by using DBDUV. The decomposition rate of toluene is increased up to $30 \%$ for the same time. This value is almost two times more than the sum of decomposition rate of toluene obtained by DBD and UV 
when they used separately. It means some synergetic effect is present in this case.

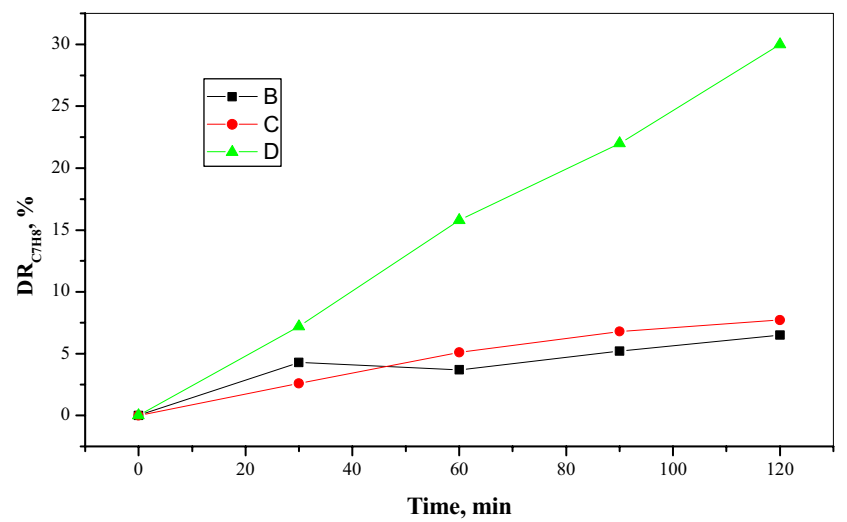

Figure 2: Toluene decomposition rate in metal chamber $\left(0.5 \mathrm{~m}^{3}\right)$ by DBD (B), UV (C) and DBDUV. Discharge voltage was $2.8 \mathrm{kV}$ : Initial concentration $\left(\mathrm{C}_{0}\right)$ of toluene were: $\left(\mathrm{C}_{0}\right)_{\mathrm{B}}=3.48 \mathrm{ppm} ;\left(\mathrm{C}_{0}\right)_{\mathrm{C}}=$ 2.54ppm; $\left(\mathrm{C}_{0}\right)_{\mathrm{D}}=3.52 \mathrm{ppm}$.

It is well known an ozone formation is a main problem by utilizing DBD for air pollution control because it is strongly regulated by the occupational safety health administration.

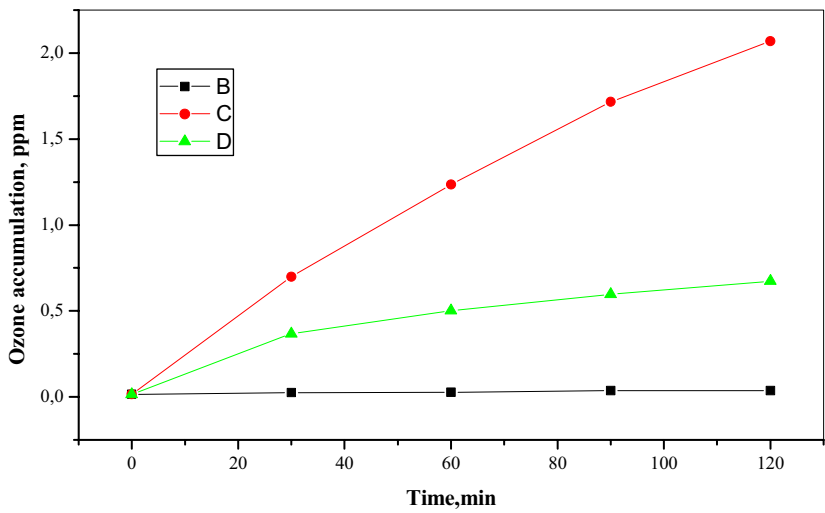

Figure 3: Ozone accumulation in metal chamber $\left(0.5 \mathrm{~m}^{3}\right)$ by UV (B), by DBD (C), and DBDUV (D). Discharge voltage was $2.8 \mathrm{kV}$.

In fig. 3 are shown the ozone accumulation concentrations which measured during toluene decomposition by three methods: DBD, UV, and DBDUV.

The accumulation concentration of ozone was significantly lower during toluene decomposition by DBDUV in comparison with DBD. It was $0.5 \mathrm{ppm}$ for 
2 hour only whereas ozone accumulation concentration for DBD was $2.0 \mathrm{ppm}$ for the same time. Ozone concentration was not practically changed during toluene decomposition by UV.

Ion clusters forming during DBD operation is one of parameters indicating the quality of air cleaner because they play important role in the indoor environment [7]. The higher the concentration of ion clusters the higher quality of the air cleaner. In fig. 4 are shown the ion concentrations accumulated in the blank metal chamber by operation of DBD, UV, and DBDUV.

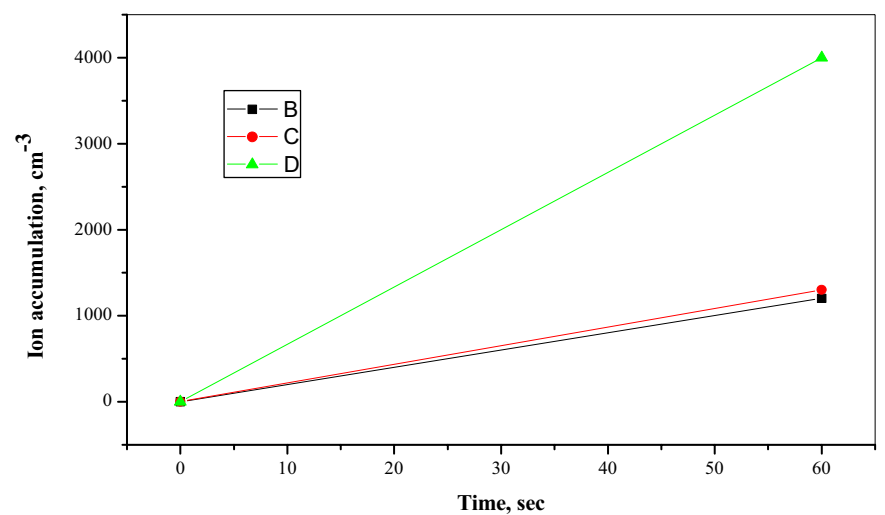

Figure 4: Ion accumulation in blank metallic chamber $\left(0.5 \mathrm{~m}^{3}\right)$ by UV (B), DBD (C), DBDUV (D). Discharge voltage was $2.8 \mathrm{kV}$.

The data indicates the ion concentration was at the level of 4000 ion $\mathrm{cm}^{-3}$ for 60 second by DBDUV whereas for other two methods was 1000 ion $\mathrm{cm}^{-3}$ for the same time only.

The other parameter which must be controlled by application of BDP for indoor air cleaning is oxidation rate $(\mathrm{S})$ of toluene because the uncompleted oxidation products like aldehydes, organic acids, etc can be formed. The higher oxidation rate the higher the quality of air cleaner.

Obtained data indicate the oxidation rate of toluene by two methods has complicated character. It will be discussed below.

\subsection{Influence of initial concentration of toluene}

Synergetic effect for toluene decomposition by DBDUV is kept at increasing the initial concentration of toluene. As seen from figure 5 the decomposition rate of toluene by DBDUV is much higher than that of DBD. Moreover the difference between two decomposition rates is as much more as higher the initial concentration of toluene. The difference between two methods was $3.5 \mathrm{ppm}$ at initial concentration of around $16 \mathrm{ppm}$ whereas its value was $1.5 \mathrm{ppm}$ only for initial concentration of around $3 \mathrm{ppm}$.

As for the decomposition rate of toluene in dependence of initial concentration, it is decreased with increasing toluene concentration. However, it 
is necessary to note the total toluene molecules decomposed increases with increasing toluene concentration, fig. 6 .

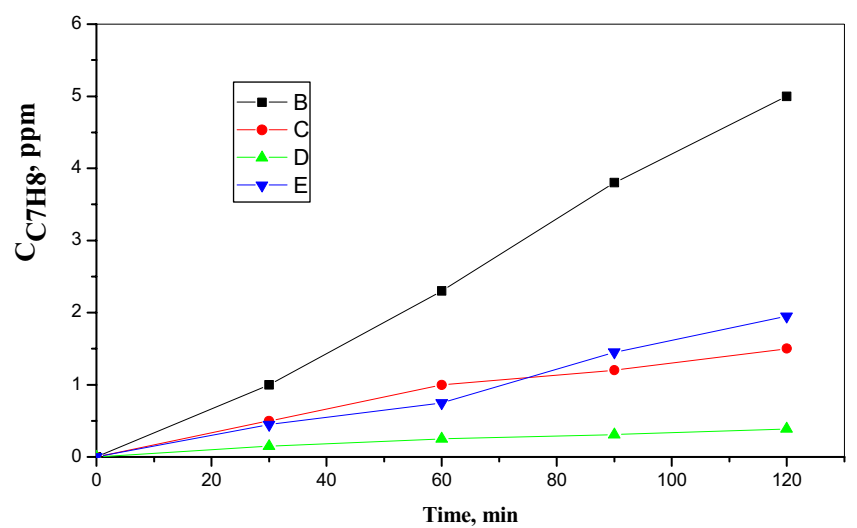

Figure 5: Toluene decomposition in metal chamber $\left(0.5 \mathrm{~m}^{3}\right)$ by DBDUV (B, E) and $\mathrm{DBD}(\mathrm{C}, \mathrm{D})$ at different concentration. Discharge voltage was $3.8 \mathrm{kV}$. Initial concentration $\left(\mathrm{C}_{0}\right)$ in ppm were: $\mathrm{C}_{0}(\mathrm{~B})=16.5$; $\mathrm{C}_{0}(\mathrm{C})=12.0 ; \mathrm{C}_{0}(\mathrm{D})=3.61 ; \mathrm{C}_{0}(\mathrm{E})=3.0$.

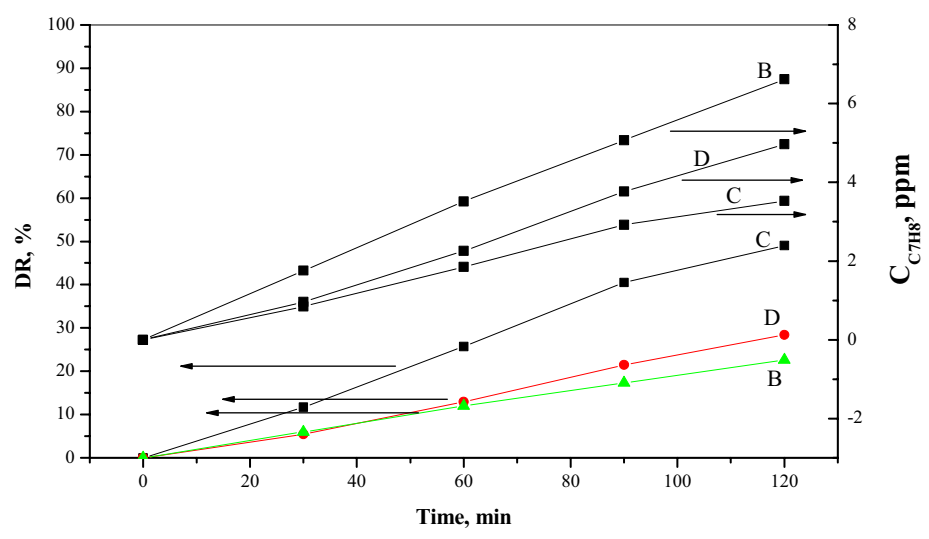

Figure 6: Toluene decomposition in metal chamber $\left(0.5 \mathrm{~m}^{3}\right)$ by DBDUV with varied initial concentrations of toluene. Discharge voltage was $3.8 \mathrm{kV}$. Initial concentrations were $\mathrm{B}-29.3 \mathrm{ppm} ; \mathrm{C}-17.5$ ppm; D - 7.2ppm.

\subsection{Influence of discharge voltage}

Discharge voltage is very important parameter for DBD because it regulates both the decomposition rate of air pollutants and the formation of by products like $\mathrm{CO}$, uncompleted oxidation compounds, and $\mathrm{O}_{3}$. 


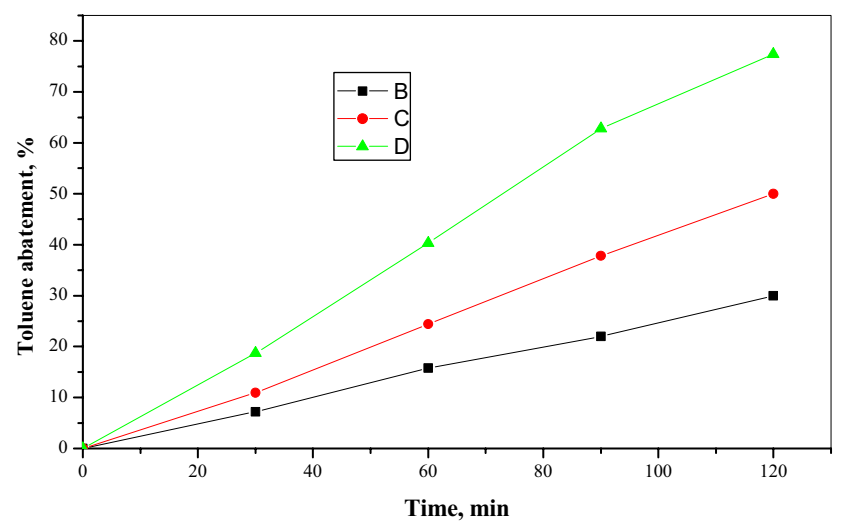

Figure 7: Toluene decomposition rate in metallic chamber $\left(0.5 \mathrm{~m}^{3}\right)$ by DBDUV at varied discharge voltages: $\mathrm{B}-2.8 \mathrm{kV}$; C $-3.4 \mathrm{kV}$; D $3.8 \mathrm{kV}$. Initial concentration of $(\mathrm{B})=3.48 \mathrm{ppm} ;(\mathrm{C})=2.54 \mathrm{ppm}$; (D) $=3.52 \mathrm{ppm}$.

In fig. 7 are shown the decomposition rates of toluene by DBDUV at three discharge voltages: $2.8,3.4$, and $3.8 \mathrm{kV}$. They indicate the higher discharge voltage the higher the decomposition rate of toluene.

In table 1 is shown data about toluene decompositions by DBD and DBDUV.

Table 1: Toluene abatement rates (\%) by BDP, UV irradiation, and combination of BDP and UV at varied discharge voltages. Treatment time was $120 \mathrm{~min}$.

\begin{tabular}{|c|c|c|c|}
\hline $\begin{array}{c}\text { High voltage, } \\
\mathbf{k V}\end{array}$ & DBD & DBDUV & DBDUV-DBD \\
\hline 2.8 & 7.5 & 30 & 22.5 \\
\hline 3.4 & 10.6 & 50 & 31.9 \\
\hline 3.8 & 12.5 & 77 & 64.5 \\
\hline
\end{tabular}

The tendency of synergetic effect for the decomposition of toluene by DBDUV is kept at varied discharge voltages too. Moreover, this effect for toluene decomposition is as much higher as the higher discharge voltage.

The difference of toluene decomposition rate between DBDUV and DBD (DBDUV-DBD) was $64.5 \%$ at $3.8 \mathrm{kV}$ whereas it was $22.5 \%$ at $2.8 \mathrm{kV}$ only.

\section{Discussion}

Synergetic effect for the decomposition of toluene by DBDUV is a very interesting and potentially useful phenomenon. In order to explain this phenomenon it is necessary to understand toluene oxidation mechanism by DBD as well as UV. 
Sekiguchi et al. [10] investigated the toluene hydroxylation by DBD plasma. They considered two types of oxygen atoms are responsible for toluene oxidation:

$\mathrm{O}\left({ }^{3} \mathrm{P}\right)-$ an atomic oxygen in the ground state;

$\mathrm{O}\left({ }^{1} \mathrm{D}\right)$ - an exited oxygen atom created by impact with $\mathrm{O}_{2}$.

The $\mathrm{O}\left({ }^{1} \mathrm{D}\right)$ is the strong oxidant for toluene to produce oxidation product such as $\mathrm{CO}$ and $\mathrm{OH}$ by breaking the aromatic structure whereas the $\mathrm{O}\left({ }^{3} \mathrm{P}\right)$ is a effective reagent for partial oxidation [10].

On other hand, Atkinson and Carter [11] showed $\mathrm{OH}$ radical is key reactive specie for most organics. The most organics react with the $\mathrm{OH}$ radical with rate constants of $\geq 5 \times 10^{-15} \mathrm{~cm}^{3}$ molecule $\mathrm{s}^{-1}$ at $298 \mathrm{~K}$ whereas an ozone reacts with toluene at the reaction rate constant of $1.2 \pm 0.6 * 10^{-20} \mathrm{~cm}^{3}$ molecule s $\mathrm{s}^{-1}$ at $298 \mathrm{~K}$ [11]. Influence of UV irradiation on the toluene oxidation was investigated by Wang and Ray [12]. They postulated the main species for toluene oxidation are also $\mathrm{OH}$ radical and $\mathrm{O}\left({ }^{1} \mathrm{D}\right)$ which can be occured by:

$$
\begin{gathered}
\mathrm{H}_{2} \mathrm{O}+\mathrm{h} v=\mathrm{H}^{\bullet}+\mathrm{OH}^{\bullet} . \\
\mathrm{H}_{2} \mathrm{O}+\mathrm{h} v=\mathrm{H}_{2}+\mathrm{O}\left({ }^{3} \mathrm{P}\right) \text { or } \mathrm{O}\left({ }^{1} \mathrm{D}\right)
\end{gathered}
$$

According to this review, synergetic effect obtained at a toluene decomposition by DBDUV is associated with the formation of additional amount of hydroxyl radical which can be formed from ozone due to [11]:

$$
\begin{gathered}
\mathrm{O}_{3}+\mathrm{h} v(\lambda \leq 310 \mathrm{~nm})=\mathrm{O}\left({ }^{1} \mathrm{D}\right)+\mathrm{O}_{2}\left({ }^{1} \Delta_{\mathrm{g}}\right) \\
\mathrm{O}\left({ }^{1} \mathrm{D}\right)+\mathrm{H}_{2} \mathrm{O}=2 \mathrm{OH}^{\bullet}
\end{gathered}
$$

Maybe it confirms indirectly by that the ozone accumulation is dramatically decreased by DBDUV in comparison by DBD, fig. 3, at constant ozone production rate which was $0.048 \mathrm{ml} / \mathrm{min}$ at discharge voltage $2.8 \mathrm{kV}$. These differences between two methods are as much higher as higher discharge voltage in the range of 2.8 to $3.8 \mathrm{kV}$, table 2 .

Table 2: Ozone accumulation (ppm) in metal chamber during toluene decomposition by DBD, UV, and DBDUV. Treatment time was $120 \mathrm{~min}$.

\begin{tabular}{|c|c|c|c|}
\hline $\begin{array}{c}\text { High } \\
\text { voltage, } \mathbf{k V}\end{array}$ & DBD & UV irradiation & DBDUV \\
\hline 2.8 & 2.07 & 0.02 & 0.67 \\
\hline 3.4 & 3.95 & 0.02 & 1.56 \\
\hline 3.8 & 5.20 & 0.02 & 2.06 \\
\hline
\end{tabular}


In table 3 are shown the parameters $(\mathrm{S})$ indicating the accumulation of $\mathrm{CO}$ and $\mathrm{CO}_{2}$ during toluene decomposition. $\boldsymbol{\Delta}_{\mathrm{C} 7 \mathrm{H} 8}$ is the decomposed toluene concentration and $\boldsymbol{\Delta} \mathrm{C}_{\mathrm{CO} 2}$ as well as $\boldsymbol{\Delta} \mathrm{C}_{\mathrm{CO}}$ are carbon dioxide and carbon monoxide concentrations, respectively.

Table 3: Selectivity to $\mathrm{CO} 2$ and $\mathrm{CO}$ for toluene oxidation by two methods: plasma and combination of plasma and UV irradiation.

\begin{tabular}{|c|c|c|c|c|c|c|c|c|}
\hline $\begin{array}{l}\text { DV } \\
\mathrm{kV}\end{array}$ & $\begin{array}{l}\text { UV } \\
\text { lig } \\
\text { ht }\end{array}$ & $\begin{array}{c}\Delta \mathrm{C}_{\mathrm{C} 7 \mathrm{H}} \\
{ }^{8} \mathrm{ppm}\end{array}$ & $\begin{array}{c}\mathbf{C}_{\mathrm{CO}}, \\
\mathbf{p p m}, \\
\text { by } \\
\text { gastec }\end{array}$ & $\begin{array}{c}\mathrm{C}_{\mathrm{CO} 2}, \\
\text { ppm, } \\
\text { by } \\
\text { gastec }\end{array}$ & 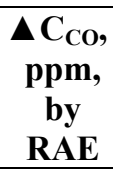 & $\begin{array}{c}\mathbf{\Delta} \mathbf{C}_{\mathrm{CO} 2}, \\
\text { ppm, } \\
\text { by } \\
\text { RAE }\end{array}$ & $\begin{array}{c}S \\
\text { by } \\
\text { gas } \\
\text { tec }\end{array}$ & $\begin{array}{c}\text { S } \\
\text { by } \\
\text { RA } \\
\text { E }\end{array}$ \\
\hline 2.8 & no & 10 & 5 & 70 & 2 & -150 & 1.1 & $-\overline{-}$ \\
\hline 2.8 & yes & 12.1 & 10 & -100 & 4 & 100 & $\begin{array}{c}- \\
1.1\end{array}$ & 1.2 \\
\hline 3.4 & no & 15 & 10 & 100 & 9 & -40 & 1.0 & $\begin{array}{c}- \\
0.3\end{array}$ \\
\hline 3.4 & yes & 16.3 & 15 & 0 & 13 & 70 & 0.1 & 0.7 \\
\hline 3.8 & no & 23 & 20 & 100 & 9 & -80 & 0.8 & $\begin{array}{c}- \\
0.4\end{array}$ \\
\hline 3.8 & yes & 25.4 & 30 & 100 & 23 & 150 & 0.7 & 1.0 \\
\hline
\end{tabular}

The parameters $(\mathrm{S})$ defined on the base of $\mathrm{CO}_{2}$ and $\mathrm{CO}$ measurements by Gastec and RAE devices are quite different. Moreover some values of them has negative one. It could be explained by formation of different by-products at different reaction conditions influencing on the readings of $\mathrm{CO}_{2}$. It could be the products of partial oxidation of toluene. Our attempt to segregate these byproducts was not successful. According to [10] the by-products of partial oxidation of toluene were $\mathrm{C}_{4^{-}}$compounds such as butadiene and other hydrocarbons which were also not identified completely.

On other hand, it indicates the oxidation rate of toluene depends on the discharge voltage of DBD plasma and can be controlled by variation of this parameter. It will be a next subject of further study.

\section{Conclusions}

The decomposition of toluene by DBD plasma as well as the combination of DBD and UV irradiation was carried out in closed metal chamber. The experimental data suggested that the synergetic effect were occurred both in the decomposition of toluene and decreasing ozone accumulation in the reaction region by means of combination of DBD and UV. The decomposition rate of toluene was dramatically increased whereas ozone concentration decreased significantly in comparison with DBD. 


\section{References}

[1] Oda, T., Takahashi, T. and Yamaji, K., "Nonthermal plasma processing for dilute VOCs decomposition". IEEE Trans. Ind. Appl. 38, pp.873-978, May/Yune 2002.

[2] Oda, T., "Non-thermal plasma processing for environmental protection: dilute VOCs decomposition in air". J. Electrostatics. 57. pp.293-311, 2003.

[3] Nishikawa, K. and Nojima, H., "Air purification effect of positively and negatively charged ions generated by discharge plasma at atmospheric pressure". Jpn. J. Appl. Phys., 40. pp. L835-L837, 2001.

[4] Daniels, S.L., "On the ionization of air for removal of noxious effluvia (Air ionization of indoor environments for control of volatile and particulate contaminants with non-thermal plasmas generated by dielectric-barrier discharge)". IEEE Trans. Plasma Science, 30 Issue: 4, pp 1471-1481, Aug. 2002.

[5] Urashima, K. and Chang, J. S., "Removal of volatile organic compounds from air streams and industrial flue gas by non-thermal plasma rechnology". IEEE Trans. Dielect. Elect. Insulat, 7, 602-14, Oct.2000.

[6] Demidiouk, V., Moon, S. I., and Chae, J.O., "Toluene and butyl acetate removal from air by plasma-catalytic system," Catalysis Commun., vol. 4, pp. 51-56, 2003.

[7] Mizino, A., Kisanuki, Y., Noguchi, M., Katsura, S., Lee, S. H., Hong, Y. K. and Shin, S. Y., "Indoor air cleaning using a pulsed corona discharge plasma”. IEEE Trans. Ind. Appl, 35, pp1284-88, 1999.

[8] Kinoshita, K., Fujiyama, Y., Kim, H. H., Katsura, S. and Mizuno, A., "Control of tobacco smoke and odors using discharge plasma reactor". $J$. Electrostatics, 42, pp83-91, 1999.

[9] Pyagai, R., Demidyuk, V., Kim, J. S. and Yan, S. B., "Development of ozone decomposition fan". Proc. of the seminar on Korean Society of odor Research and Eng, pp. 86-91, Nov.2005.

[10] Sekiguchi, H., Ando, M., and Kojima, H., "Study of hydroxylation of benzene and toluene using a micro-DBD plasma reactor". J. Phys. D: Appl. Phys. 38, pp1722-27, 2005.

[11] Atkinson, R. and Carter, W. P. L., "Kinetics and mechanisms of the gasphase reactions of ozone with organic compounds under atmospheric conditions". Chem. Rew, 84, 437-70, 1984.

[12] Wang J.H., Ray M.B., Application of ultraviolet photooxidation to remove organic pollutants in the gas phase". Separation and Purification Technology, 19, 11-20, 2000. 